\begin{tabular}{|c|c|c|}
\hline Case Reports in & \multicolumn{2}{|c|}{ Case Rep Gastroenterol 2013;7:332-339 } \\
\hline iastroenterology & $\begin{array}{l}\text { DOI: 10.1159/000354136 } \\
\text { Publisned online: August 16, } 2013\end{array}$ & $\begin{array}{l}\text { ○ } 2013 \text { S. Karger AG, Basel } \\
1662-0631 / 13 / 0072-0332 \$ 38.00 / 0 \\
\text { www.karger.com/crg }\end{array}$ \\
\hline & \multicolumn{2}{|c|}{$\begin{array}{l}\text { This is an Open Access article licensed under the terms of the Creative Common } \\
\text { Attribution-NonCommercial } 3.0 \text { Unported license (CC BY-NC) (www.karger.com/OA } \\
\text { license), applicable to the online version of the article only. Distribution permitted for non } \\
\text { commercial purposes only. }\end{array}$} \\
\hline
\end{tabular}
commercial purposes only.

\title{
Incidence of Pancreatic Fistula after Distal Pancreatectomy and Efficacy of Endoscopic Therapy for Its Management: Results from a Tertiary Care Center
}

\author{
Savio C. Reddymasu ${ }^{\mathrm{a}}$ Kavous Pakseresht $^{\mathrm{b}}$ Brian Moloney $^{\mathrm{b}}$ \\ Benjamin Alsop $^{b} \quad$ Melissa Oropezia-Vail ${ }^{b} \quad$ Mojtaba Olyaee ${ }^{a}$ \\ ${ }^{a}$ Division of Gastroenterology and Hepatology, Department of Internal Medicine, \\ Creighton University Medical Center, Omaha, Nebr., and ${ }^{b}$ Division of Gastroenterology \\ and Hepatology, Department of Internal Medicine, University of Kansas Medical Center \\ Kansas City, Kans., USA
}

\section{Key Words}

Distal pancreatectomy $\cdot$ Pancreatic fistula $\cdot$ Pancreatic leak $\cdot$ Pancreatic duct stenting

\begin{abstract}
Pancreatic fistula is a known complication of distal pancreatectomy. Endotherapy with pancreatic duct stent placement and pancreatic sphincterotomy has been shown to be effective in its management; however, experience of endotherapy in the management of this complication has not been extensively reported from the United States. Preoperative endoscopic retrograde cholangiopancreatography $(E R C P)$ with pancreatic stent placement has also been proposed to prevent this complication after distal pancreatectomy. In our cohort of 59 patients who underwent distal pancreatectomy, 13 (22\%) developed a pancreatic fistula in the immediate postoperative period, of whom 8 (14\%) patients ( 5 female, mean age 52 years) were referred for an ERCP because of ongoing symptoms related to the pancreatic fistula. The pancreatic fistula resolved in all patients after a median duration of 62 days from the index ERCP. The median number of ERCPs required to document resolution of the pancreatic fistula was 2. Although a sizeable percentage of patients develop a pancreatic fistula after distal pancreatectomy, only a small percentage of patients require ERCP for management of this complication. Given the high success rate of endotherapy in resolving pancreatic fistula and the fact that the majority of patients who undergo distal pancreatectomy never require
\end{abstract}

Mojtaba Olyaee, MD

University of Kansas Medical Center

2085 Delp Pavilion, 3901 Rainbow Boulevard

Kansas City, KS 66160 (USA)

E-Mail molyaee@kumc.edu 
Reddymasu et al.: Incidence of Pancreatic Fistula after Distal Pancreatectomy and Efficacy of Endoscopic Therapy for Its Management

an ERCP, performing ERCP for prophylactic pancreatic duct stent prior to distal pancreatectomy might not be necessary.

(c) 2013 S. Karger AG, Basel

\section{Introduction}

Distal pancreatectomy with or without splenectomy is performed for the management of pancreatic lesions that arise left of the superior mesenteric vein. It accounts for about $25 \%$ of all pancreatic resections performed for solid or cystic lesions arising in the distal body or the tail of the pancreas [1]. This surgery is fairly well tolerated with an overall mortality rate of about $3 \%$ or less [2]. However, some patients develop pancreatic fistula as a complication of this procedure, which accounts for significant post procedure morbidity. The incidence of this complication can be as high as $26 \%$, however it tends to be much lower (in the $5 \%$ range) in high-volume centers [1-3]. Some of the risk factors associated with pancreatic fistula after distal pancreatectomy include decreased albumin level, concurrent splenectomy, increased body weight, increased duration of surgery, higher American Society of Anesthesiologists score and impaired renal function [4-6]. A number of interventions such as sealing of the pancreatic duct stump with fibrin glue [7] or BioGlue [8], use of perioperative octreotide or variations in surgical techniques have been proposed to minimize the occurrence of pancreatic fistula after distal pancreatectomy, however pancreatic fistula tends to occur despite these interventions.

The efficacy of endotherapy in helping resolve pancreatic fistula after distal pancreatectomy has been described in the past, mostly in studies reported from Europe $[9,10]$ and more recently by a group from the United States [11]. Recently, even the use of preoperative pancreatic duct stenting to prevent postoperative pancreatic fistula has been explored in two studies, one from Germany [12] and one from Japan [13], and both these studies concluded that this intervention prevented the development of pancreatic fistula after distal pancreatectomy. However, the feasibility of this practice has never been explored in the United States.

Since the experience of endotherapy for the management of post distal pancreatectomy pancreatic fistulas in the United States has not been widely reported, the aim of this study was to estimate the incidence of pancreatic fistula after distal pancreatectomy (with or without splenectomy) and to evaluate the efficacy of endoscopic therapy in the management of this complication in our tertiary care center.

\section{Methods}

\section{Subjects}

The surgical pathology database at the University of Kansas Medical Center was queried for patients who underwent 'pancreatectomy', 'distal pancreatectomy' and 'splenectomy'. The endoscopy database at our institution was also queried for patients who underwent endoscopic retrograde cholangiopancreatography (ERCP) between January 2005 and July 2010 for evaluation of 'pancreatic leak' or 'pancreatic fistula'. Baseline demographics, duration between successive ERCPs and pancreatography findings on index and successive ERCPs were reviewed. Depending on the severity of distal occlusion failure, patients were classified into three categories based on the International Study Group on Pancreatic Fistula Working Group (ISGPFWG) grading criteria: (i) Grade A: patients whose pancreatic fistula resolves spontaneously without the need for any intervention. (ii) Grade B: there is a re- 
Reddymasu et al.: Incidence of Pancreatic Fistula after Distal Pancreatectomy and Efficacy of Endoscopic Therapy for Its Management

quirement for change in clinical management due to the pancreatic fistula, however patients are not severely ill. (iii) Grade C: severely ill and septic patients due to refractory pancreatic fistula that necessitates a major change in clinical management. This study was approved by the Human Subjects Committee at the University of Kansas Medical Center.

\section{Endoscopic Data}

The ERCP reports of all patients who met the inclusion criteria for the study were reviewed. The following data were extracted: (a) presence or absence of a pancreatic fistula on the initial or subsequent ERCP, (b) location of the pancreatic fistula, (c) type of intervention performed during ERCP, such as placement of a stent, sphincterotomy, etc., and (d) complications, if any, during the procedure.

If a stent is placed during the initial ERCP, as a practice pattern we perform repeat ERCP within about 6-8 weeks. The stent is replaced if the pancreatic fistula is found on the subsequent ERCP up until complete resolution of the pancreatic fistula is documented. The ERCP is performed earlier if there is any clinical suspicion of stent occlusion. Care was taken to avoid high-pressure injection into the pancreatic duct to prevent reopening of the pancreatic fistula. All ERCP procedures were performed by an experienced endoscopist (M.0.) who performs 400-500 ERCPs annually.

\section{Statistical Analysis}

Data are expressed as percentages for categorical variables and median values for linear variables, unless specified otherwise. Student's test was used to analyze linear variables where necessary. $\mathrm{p}<0.05$ was used for statistical significance.

\section{Results}

During the study period, 59 patients ( 41 female) underwent distal pancreatectomy, of whom 48 also underwent concurrent splenectomy. The mean age of the patients in this cohort was 55 years (range 23-83). Thirteen patients (22\%) developed pancreatic fistula in the immediate postoperative period. Five of these patients (8\%) improved spontaneously (grade A) with placement of a percutaneous drain. Eight (14\%) patients (5 female, mean age 52 years) met the criteria for ISGPFWG grade B pancreatic fistula and were referred for an ERCP for ongoing symptoms. The ERCP was performed after a median duration of 42 days (range 13-85) after surgery. Cannulation of the pancreatic duct was successful in all patients. Pancreatic fistula was documented in the initial ERCP in all patients and a representative pancreatography image is depicted in figure 1. A 5-French plastic stent of varying size (3-8 cm long) was placed in the pancreatic duct during the index ERCP in all patients to help resolve the pancreatic fistula (representative pancreatogram in fig. 2). Pancreatic sphincterotomy was not performed in any of the patients. The median number of ERCPs required to document resolution of the pancreatic fistula (representative pancreatogram in fig. 3) was 2 (range 2-10). All patients had resolution of the pancreatic fistula after a median duration of 62 days (range 28-379). Individual patient characteristics, details and number of endoscopic interventions, and patient outcomes are presented in table 1. No serious complications were reported with any of the ERCP procedures. 
Reddymasu et al.: Incidence of Pancreatic Fistula after Distal Pancreatectomy and Efficacy of Endoscopic Therapy for Its Management

\section{Discussion}

The results of our study indicate that pancreatic fistula after distal pancreatectomy occurs in a sizeable percentage of patients. Some of these patients are referred in consideration for endotherapy as the pancreatic fistula does not resolve spontaneously. Transpapillary pancreatic duct stent placement appears to be effective in this scenario as shown by the results above. Most patients have resolution of the pancreatic fistula by the time of the second ERCP, however a few patients require repeated ERCPs to help with healing of the pancreatic fistula. The efficacy of endotherapy for resolution of pancreatic fistula in our series of patients is comparable to other studies [9-11]. A variety of techniques have been described for the management of post distal pancreatectomy pancreatic fistula, including use of 5- or 7-French stents and performance of concurrent pancreatic sphincterotomy. No head to head comparisons were made between these different techniques to establish superiority of one technique over the other. However, it could be argued that in the patients in our cohort who took longer than expected to resolve the pancreatic fistula, performing a pancreatic sphincterotomy or placing a larger-caliber pancreatic duct stent could have reduced the transpapillary pressure gradient even further and helped accelerate the healing process of the fistula.

Pancreatic fistula after distal pancreatectomy is a serious complication that is associated with significant utilization of health care resources. The health-related costs are almost doubled in patients with this complication after distal pancreatectomy [14]. Hence, any strategy to minimize or eliminate the risk of pancreatic fistula after distal pancreatectomy will not only minimize morbidity related to the procedure, but also result in significant cost savings for the patient. To this effect, several strategies are being investigated, including the use of fibrin glue and BioGlue as well as alterations in surgical techniques for closure of the pancreatic remnant. However, none of these have proven to be 'fool proof' in the prevention of post distal pancreatectomy pancreatic fistula. Recently, prophylactic pancreatic duct stenting by ERCP has been explored as another strategy to prevent pancreatic fistula after distal pancreatectomy, and it appears to be very effective in preventing this complication $[12,13]$.

All the studies focusing on prophylactic pancreatic duct stent placement to prevent post distal pancreatectomy pancreatic fistula were performed in Europe or Japan. In a recent German case-control study, in the intention to treat analysis, 8 ERCPs with pancreatic duct stent placement needed to be performed to prevent one grade B or C pancreatic fistula. It is unclear how this practice pattern would fit in the United States health care system, considering the number of ERCPs that need to be performed to prevent one pancreatic fistula formation. The medical malpractice litigation related to ERCP [15] in the United States could also be a deterrent to gastroenterologists to perform this procedure for this indication at this time. The other factor that needs to be considered is that the majority of patients who undergo distal pancreatectomy never require an ERCP, and even in those who require an ERCP, the pancreatic fistula resolves within a couple of months, and not more than 2 ERCPs are required in the majority of patients. If the potential complications are factored into the cost model, it is unclear whether preoperative pancreatic duct placement in all patients who undergo distal pancreatectomy would be financially feasible. Targeting prophylactic pancreatic duct stent placement to those patients who are at high risk for developing post distal pancreatectomy pancreatic fistula based on preoperative characteristics such as low albumin level, elevated creatinine, age $<65$ years or higher American Society of Anesthesiologist score appears to be an attractive option, however this has not been shown in a controlled setting. 
Reddymasu et al.: Incidence of Pancreatic Fistula after Distal Pancreatectomy and Efficacy of Endoscopic Therapy for Its Management

The limitations of our study are that it is a retrospective study, the relatively small number of patients who underwent endotherapy for post distal pancreatectomy pancreatic fistula, and the inability to determine which patient has a higher risk of pancreatic fistula formation or what patient characteristics are associated with the requirement for multiple endoscopic interventions for fistula closure. It could be pointed out that in our study, we used pancreatic duct stents of different sizes and that this could account for varying clinical outcomes. The pancreatic duct stent size was chosen based on the pancreatic duct anatomy. Also, it could be argued that in the 2 patients who had multiple procedures (ERCPs) to document fistula closure, injecting contrast with high pressure into the pancreatic duct may have reopened the pancreatic duct fistula, leading to subsequent pancreatic duct stenting, however care was taken to avoid this phenomenon during the procedure. These patients continued to undergo ERCPs as opposed to definitive surgery as they were felt to be poor surgical candidates.

In conclusion, our study shows that a sizeable percentage of patients develop a pancreatic fistula after distal pancreatectomy. Endotherapy with pancreatic duct stent helps to resolve this complication, albeit some patients require multiple sessions before the fistula closes. Given the fact that the majority of patients who undergo this surgery never require an ERCP, performing ERCP for prophylactic pancreatic duct stent placement prior to distal pancreatectomy to prevent a pancreatic fistula might not be a cost-effective strategy. Future research should focus on identifying and targeting patients who might benefit most from prophylactic pancreatic duct stenting in this scenario.

\section{Disclosure Statement}

The authors make no financial disclosure.

\section{References}

1 Balcom JH 4th, et al: Ten-year experience with 733 pancreatic resections: changing indications, older patients, and decreasing length of hospitalization. Arch Surg 2001;136:391-398.

-2 Lillemoe KD, et al: Distal pancreatectomy: indications and outcomes in 235 patients. Ann Surg 1999;229: 693-698; discussion 698-700.

-3 Fahy BN, et al: Morbidity, mortality, and technical factors of distal pancreatectomy. Am J Surg 2002;183: 237-241.

4 Goh BK, et al: Critical appraisal of 232 consecutive distal pancreatectomies with emphasis on risk factors, outcome, and management of the postoperative pancreatic fistula: a 21-year experience at a single institution. Arch Surg 2008;143:956-965.

5 Sledzianowski JF, et al: Risk factors for mortality and intra-abdominal morbidity after distal pancreatectomy. Surgery 2005;137:180-185.

6 Adam U, et al: Pancreatic leakage after pancreas resection. An analysis of 345 operated patients (in German). Chirurg 2002;73:466-473.

7 Suc B, et al: Temporary fibrin glue occlusion of the main pancreatic duct in the prevention of intraabdominal complications after pancreatic resection: prospective randomized trial. Ann Surg 2003;237: 57-65.

8 Fisher WE, et al: Effect of BioGlue on the incidence of pancreatic fistula following pancreas resection. J Gastrointest Surg 2008;12:882-890.

-9 Goasguen N, et al: Endoscopic management of pancreatic fistula after distal pancreatectomy and enucleation. Am J Surg 2009;197:715-720.

10 Costamagna G, et al: Endoscopic treatment of postsurgical external pancreatic fistulas. Endoscopy 2001;33:317-322.

11 Grobmyer SR, et al: Pancreatic stent placement is associated with resolution of refractory grade C pancreatic fistula after left-sided pancreatectomy. Am Surg 2009;75:654-657; discussion 657-658. 
Reddymasu et al.: Incidence of Pancreatic Fistula after Distal Pancreatectomy and Efficacy of Endoscopic Therapy for Its Management

12 Rieder B, et al: Endoscopic pancreatic sphincterotomy and stenting for preoperative prophylaxis of pancreatic fistula after distal pancreatectomy. Gastrointest Endosc 2010;72:536-542.

13 Abe N, et al: Preoperative endoscopic pancreatic stenting: a novel prophylactic measure against pancreatic fistula after distal pancreatectomy. J Hepatobiliary Pancreat Surg 2008;15:373-376.

14 Rodriguez JR, et al: Implications and cost of pancreatic leak following distal pancreatic resection. Arch Surg 2006;141:361-365; discussion 366.

15 Cotton PB: Analysis of 59 ERCP lawsuits; mainly about indications. Gastrointest Endosc 2006;63:378-382; quiz 464 .

Parts of the manuscript were presented in abstract form at the AGA Annual Meeting 2011 in Chicago, Ill., USA.

Table 1. Baseline characteristics and procedural details of patients who underwent endotherapy for pancreatic fistula following distal pancreatectomy

\begin{tabular}{|c|c|c|c|c|c|c|c|c|c|}
\hline $\begin{array}{l}\text { Pa- } \\
\text { tient }\end{array}$ & Age & Gender & $\begin{array}{l}\text { Nature of } \\
\text { the pancreatic } \\
\text { lesion }\end{array}$ & Type of surgery & $\begin{array}{l}\text { Time between } \\
\text { surgery and } \\
\text { index ERCP, } \\
\text { days }\end{array}$ & Type of stent placed & $\begin{array}{l}\text { Total number of } \\
\text { ERCPs to document } \\
\text { resolution of the } \\
\text { pancreatic fistula }\end{array}$ & $\begin{array}{l}\text { Duration for } \\
\text { resolution of } \\
\text { the pancreatic } \\
\text { fistula, days }\end{array}$ & $\begin{array}{l}\text { Compli- } \\
\text { cations }\end{array}$ \\
\hline 1 & 52 & male & solid lesion & distal pancreatectomy & 85 & 5 French, $6 \mathrm{~cm}$ & 3 & 105 & no \\
\hline 2 & 60 & male & cystic lesion & $\begin{array}{l}\text { distal pancreatectomy/ } \\
\text { splenectomy }\end{array}$ & 27 & 5 French, $4 \mathrm{~cm}$ & 2 & 62 & no \\
\hline 3 & 39 & female & cystic lesion & $\begin{array}{l}\text { distal pancreatectomy/ } \\
\text { splenectomy }\end{array}$ & 58 & 5 French, $6 \mathrm{~cm}$ & 2 & 58 & no \\
\hline 4 & 56 & female & cystic lesion & $\begin{array}{l}\text { distal pancreatectomy/ } \\
\text { splenectomy }\end{array}$ & 37 & 5 French, $8 \mathrm{~cm}$ & 10 & 379 & no \\
\hline 5 & 69 & female & cystic lesion & $\begin{array}{l}\text { distal pancreatectomy/ } \\
\text { splenectomy }\end{array}$ & 69 & 5 French, $8 \mathrm{~cm}$ & 2 & 48 & no \\
\hline 6 & 50 & female & cystic lesion & distal pancreatectomy & 13 & 5 French, $4 \mathrm{~cm}$ & 2 & 44 & no \\
\hline 7 & 61 & female & solid lesion & distal pancreatectomy & 37 & 5 French, $6 \mathrm{~cm}$ & 4 & 143 & no \\
\hline 8 & 53 & male & solid lesion & $\begin{array}{l}\text { distal pancreatectomy/ } \\
\text { splenectomy }\end{array}$ & 38 & 5 French, $3 \mathrm{~cm}$ & 2 & 62 & no \\
\hline
\end{tabular}




\begin{tabular}{rll} 
Case Reports in & \multicolumn{2}{l}{ Case Rep Gastroenterol 2013;7:332-339 } \\
\cline { 2 - 3 } Gastroenterology & DOI: 10.1159/000354136 & $\begin{array}{l}\text { ○ 2013 S. Karger AG, Basel } \\
\text { www.karger.com/crg }\end{array}$ \\
\hline
\end{tabular}

Reddymasu et al.: Incidence of Pancreatic Fistula after Distal Pancreatectomy and Efficacy of Endoscopic Therapy for Its Management

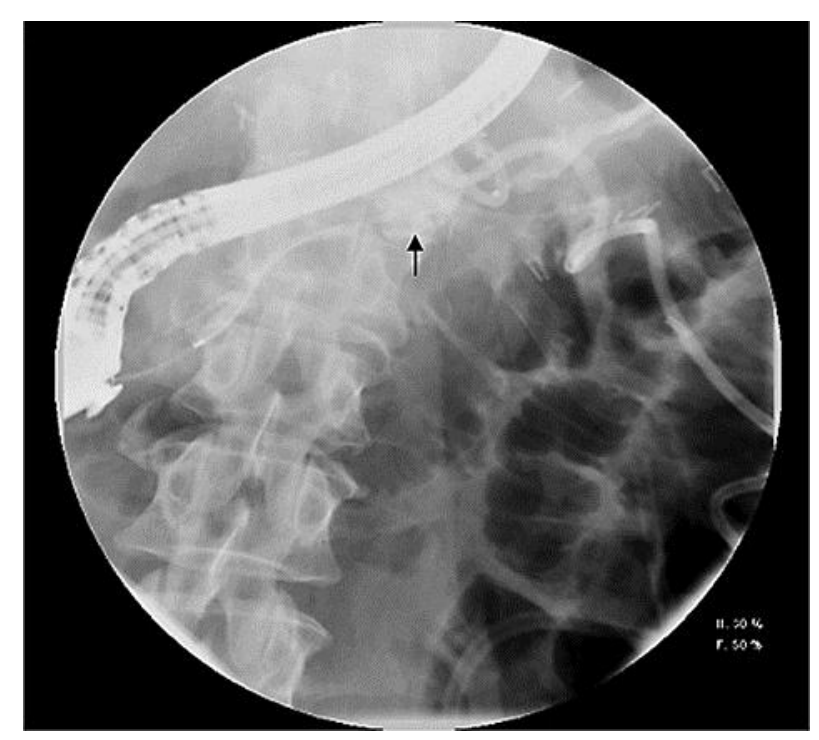

Fig. 1. Pancreatogram demonstrating a pancreatic fistula after distal pancreatectomy (arrow).

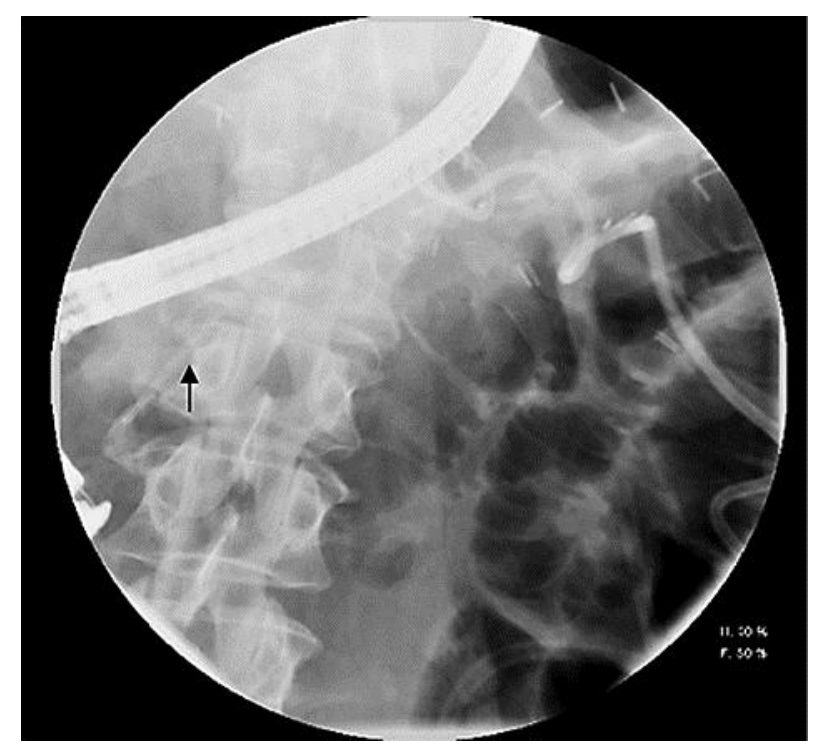

Fig. 2. Pancreatogram demonstrating pancreatic duct stent placement (arrow). 


\begin{tabular}{rl|l}
$\begin{aligned} \text { Case Reports in } \\
\text { Gastroenterology }\end{aligned}$ & \begin{tabular}{l} 
Case Rep Gastroenterol 2013;7:332-339 \\
\cline { 2 - 3 } DOI: $10.1159 / 000354136$
\end{tabular} & $\begin{array}{l}\text { (2013 S. Karger AG, Basel } \\
\text { ww.karger.com/crg }\end{array}$ \\
\hline
\end{tabular}

Reddymasu et al.: Incidence of Pancreatic Fistula after Distal Pancreatectomy and Efficacy of Endoscopic Therapy for Its Management

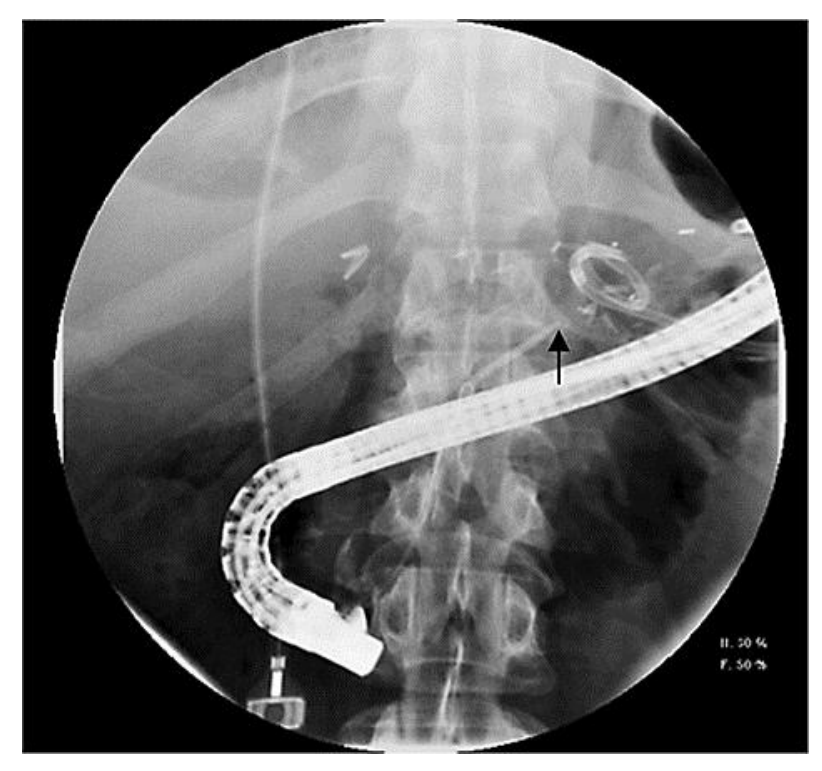

Fig. 3. Pancreatogram demonstrating resolution of the pancreatic fistula (arrow). 